\title{
Mechanisims of asthma and allergic disease - 1081. Resolvin inhibits the cryopyrin/nalp3 inflammasome
}

\author{
Cox Ruan, Narasaiah Kolliputi \\ From 2nd WAO International Scientific Conference (WISC 2012) \\ Hyderabad, India. 6-9 December 2012
}

\section{Background}

The inflammasome is a novel protein complex that stimulates caspase- 1 activation to promote the processing and secretion of IL-1 $\beta$, a pro-inflammatory cytokine, which is among the most biologically important inflammatory mediators in allergic airway diseases. Among the various types of inflammasomes, Cryopyrin/NALP3 has been suggested to be involved in sensing sterile stress response, extracellular ATP, danger-associated molecular patterns (DAMPs), and crystals. Recently inappropriate NALP3 inflammasome activity has been reported in various allergic airway diseases including asthma. Therefore, inhibitors of the NALP3 inflammasome offer considerable therapeutic promise. Recently Omega-3 fatty acid derivates termed resolvins have shown to alter the effects of pro-inflammatory cytokine storm seen in inflammatory diseases. However the ability of resolvins to modulate the effects of inflammasome activation has not been studied. We investigated whether resolvin treatment inhibits inflammasome activation and regulates the functional effects of inflammasome mediated by IL-1 $1 \beta$ secretion.

\section{Methods}

In our study the inflammasome was activated by ATP and $\mathrm{H}_{2} \mathrm{O}_{2}$ (known nflammasome activators in acute lung injury) in the absence or presence of $\mathrm{D}$ series resolvins, resolvin D1 and resolvin D2. Inflammasome activation was assessed by analyzing IL- $1 \beta$ release (end product of inflammasome activation) and caspase- 1 cleavage (indicator of inflammasome activation) in THP-1 cells. Further inflammasome was activated in the presence or absence of resolvin in THP-1 cells, and supernatants from these cells were added to A549 cells and human primary small airway epithelial cells (HPSAEC) to study inflammasome mediated functional effects.

Internal Medicine, University of South Florida, Tampa, USA

\section{Results}

Our results indicate that resolvin treatment ameliorates inflammasome activation as indicated by decreased caspase- 1 activity and IL- $1 \beta$ release. In addition resolvin treatment inhibits inflammasome mediated epithelial cell activation as indicated by suppressed IL- 8 release and decreased and ICAM expression.

\section{Conclusions}

These novel findings suggest that resolvins can be used to modulate the inflammasome activity as well as blunt the effects of the IL- $1 \beta$ mediated cytokine storm stemming from inflammasome activation. These results may offer a therapeutic approach to airway diseases such as asthma, where ungoverned pro-inflammatory cytokine secretion exacerbates the disease pathology.

Published: 23 April 2013

doi:10.1186/1939-4551-6-S1-P77

Cite this article as: Ruan and Kolliputi: Mechanisims of asthma and allergic disease - 1081. Resolvin inhibits the cryopyrin/nalp3

inflammasome. World Allergy Organization Journal 2013 6(Suppl 1):P77.

Submit your next manuscript to BioMed Central and take full advantage of:

- Convenient online submission

- Thorough peer review

- No space constraints or color figure charges

- Immediate publication on acceptance

- Inclusion in PubMed, CAS, Scopus and Google Scholar

- Research which is freely available for redistribution 